\title{
Neuropsychological Performance of Adolescents with High and Low School Performance
}

\author{
María del Rosario Bonilla-Sánchez, Grecia Guadalupe Anguiano García, \\ Marco Antonio García Flores, Ernesto Vladimir Ramírez Arroyo
}

Master's Degree in Neuropsychological Diagnosis and Rehabilitation, Benemerita Autonomous University of Puebla, Puebla, Mexico

Email:maria.bonilla@correo.buap.mx

How to cite this paper: del Rosario Bonilla-Sánchez, M., García, G. G. A., Flores, M. A. G., \& Arroyo, E. V. R. (2018). Neuropsychological Performance of Adolescents with High and Low School Performance. Psychology, 9, 2768-2781. https://doi.org/10.4236/psych.2018.913159

Received: October 8, 2018

Accepted: December 7, 2018

Published: December 10, 2018

Copyright (c) 2018 by authors and Scientific Research Publishing Inc. This work is licensed under the Creative Commons Attribution International License (CC BY 4.0).

http://creativecommons.org/licenses/by/4.0/ Open Access

\begin{abstract}
The attainment of the school activity is comprised of the functional maturation of specific brain structures. The neuropsychological analysis enables to determine weak and strong neuropsychological factors in the course of development. The objective was to show the characteristics of the performance of normotypical adolescents during tasks which evaluate the "analysis and spatial synthesis" and "regulation and control" neuropsychological factors in adolescents with high and low academic performance. A total of 48 adolescents, between 12 and 15 years old, who attended middle school in an urban public institution in Puebla, México, were assessed. Groups of students with high (24) and low (24) academic performance of the three grades were formed. The qualitative neuropsychological assessment was process-oriented, including the specific quirks of execution of the tasks that assess the functional status of the neuropsychological factors proposed by A. R. Luria. Mixed analysis was implemented. The results reveal functional weakness of the neuropsychological factors "regulation and control" and "spatial analysis" (in the global spatial perceptual modality) in the group with low performance, and a systemic effect in the assessment tasks: visual and verbal retention and alertness. The incorporation of neuropsychology in the educational systems is the key.
\end{abstract}

\section{Keywords}

Regulation and Control, Spatial Analysis and Synthesis, Neuropsychological Performance, Adolescence

\section{Introduction}

School activity during secondary education includes the fulfillment of complex 
writing, reading and calculus tasks as essential tools to gain knowledge and the construction of reality (Méndez, 2015), such tasks require complex intellectual processes and greater demands to brain functioning, representing complex psychological activities (Akhutina \& Pylaeva, 2012). It has been proposed, in the Historical-Cultural neuropsychological approach, that complex mental processes require collaboration from the three main brain functional units. The first unit is for regulating cortical tone and the waking state, the second unit processes and stores outer information, and the third unit is for programming, regulation and verification of the activities (Luria, 1995a). The three units contribute to the fulfillment of conscious, objective-oriented, activity through the particular share of every one of the neuropsychological factors, which are regarded as the outcome of the work from a specialized brain zone or group of zones (Quintanar \& Solovieva, 2008).

On the third unit, the prefrontal areas play a decisive role in the formulation of intentions and programs, and in the regulation and verification of complex forms of human behavior; it contains rich ascending and descending connections with subcortical nuclei, as well as with almost the rest of the cortex. The modulating influence of the prefrontal area over the reticular formation gives rise to activating impulses of differential character "making them fit to the dynamic behavior schemes which are formed directly by the frontal cortex" (Luria, 1986: p. 85). There are functional changes of the different brain structures due to they maturing gradually and heterocronically during ontogeny (Solovieva, Machinskaya, Quintanar, Bonilla, \& Pelayo, 2009). The optimal functional level of the "regulation and control" neuropsychological factor can predict, since the preschool age, the academic success, especially for the learning in writing, reading and mathematics; during adolescence these actions become more complex requiring, as well as changes on the prefrontal cortex (Blair \& Razza, 2013; Solovieva, Bonilla, \& Quintanar, 2006). From the position of cognitive neuropsychology, it has been proposed that such changes may explain the late maturation of executive functions and social cognition (Cotton, 2011; Valeri, 2011; Fabes, et al., 1999). Self-regulated children can delay gratification, suppress immediate impulses and anticipate the consequences of their actions (Bodrova \& Leong, 2012), thereby they will be able to maintain the regulation and voluntary control of their actions (Akhutina, 2002).

The elementary school period is as well characterized for the functional maturation of brain structures that provide downward modulation from specific frontal lobe areas, taking part during the visuospatial information processing (Machinskaya, Semenova, Absatova, \& Sugrobova, 2014). The spatial analysis and synthesis mechanism, located on the second brain unit, guarantees the perception and production of essential features and their location (analytical component) as well as the perception and production of forms, the metric aspects and proportions of the objects (global component) (Quintanar \& Solovieva, 2008). The visuospatial analysis and synthesis involves a constellation of perceptual and constructional abilities (Bravo, 2004). The spatial analysis comprises 
the whole first and progressively, as the brain matures, the elements are analyzed, this spatial analysis is successful between 6 and 7 years of age. The way in which visuospatial information is processed has an impact on the skill with which visuoconstructional tasks are carried out (Ardila \& Rosselli, 2007) and calculation, mainly in its written form (Venneri, Cornoldi, \& Garuti, 2003). Therefore, complex functional systems are integrated during the development and maturation of the brain (Luria, 1986, 1995a). Vygotsky (1995a, 1995b), raises the social theory of cognitive development, proposing that children and adolescents learn through interaction with their social environment in collaboration with adults. In addition, in the case of school activity, high motivation from the student and adequate habits, that encourage the acquisition of cognitive skills, are required (Talizina, 2009, Córdoba, Quijano, \& Cadavid, 2013). Belonging to a socio-cultural level, living conditions and the characteristics of pedagogical methods and the educational system influence child psychological and neuropsychological development (Solovieva, Quintanar, \& Lázaro, 2006). Neuropsychology studies the relationships between the psyche and brain activity through the actions of the subject, which require the functional participation of various neuropsychological factors. Neuropsychological analysis allows to determine weak and strong neuropsychological factors during development, not only in the presence of learning disorders, but also in normotypical development conditions in regular education, where students may also have poor academic performance, understood as the difficulty to approach the level of knowledge, skills and attitudes demonstrated by students in an area or subject compared with the norm of age and academic level (Edel, 2003). In many cases, teachers and researchers approach the level of academic performance based on the student's school grades. However, it would be convenient to consider not only this, but also the intellectual development and family integration, since a high correlation between these variables and academic performance has been identified, both in upper secondary and higher level students (Muñoz, 1993). Other studies (Castillo-Parra, Gómez, \& Ostrosky-Solís, 2009) have also identified that good school performance in basic education students requires an adequate memory capacity and the development of executive functions. On the other hand, neuropsychological studies related to the level of academic performance of students of basic secondary education in public secondary are not currently reported.

The objective is to show the performance characteristics of normotypical adolescents during tasks that assess the neuropsychological factors of "analysis and spatial synthesis" and "regulation and control", with the purpose of identifying the strong and weak functional characteristics of said factors, in adolescents with high and low school performance.

\section{Method}

\subsection{Study Design}

A cross-sectional, exploratory and descriptive study was carried out. A neurop- 
sychological assessment instrument was applied to evaluate the neuropsychological factors proposed by Luria (1995a). From the performance of the syndromic analysis, the typical performances of the adolescents were obtained, the qualitative and quantitative characteristics of execution that indicated the functional state of the neuropsychological factors were analyzed, the negative and/or positive tendencies in the functional level of said factors were identified as well as their contributions to functional systems for school reading and writing activities.

\subsection{Sample Selection}

The sample was selected from the Federal High School no. 1 "President Cárdenas", in themorningshift, located in Colonia Resurgence in the City of Puebla, Mexico. The campus has a population of 700 students, onaverage, in themorningshift, dividedinto 18 groups (6 groupsforeach of thefirst, second and third grades). The students who attend this school belong to working class families with a medium-low socioeconomic level.

The sample was arranged with a total of 48 adolescents, gender indistinct, between 12 and 15 yearsold. The sampling had the advantage of taking into account high and low academic performance students. The assessment groups were formed by the managers of the participating institution according to the valuation scales stipulated by the Ministry of Public Education (SEP) in Mexico. These scales reported that highschool performance participants had obtained an average score between nine and ten ( 1 to 10 range). As for the low school performance, participants had obtained an average score between six and seven pointfive. In addition, the criteria of not repeating school grades as well as the absence of neurological, neuropsychological or psychopathological disorders clinically demonstrable in the adolescent record were taken into account. Two research groups were formed, High School Performance (HSP) (8 students) and Low School Performance (LSP) (8 students) foreach grade level.

\subsection{Instrument}

The "Brief Neuropsychological Assessment for Adolescents" was applied (unpublished), as well as an instrument based on the exercises and methodology of the "Evaluación Neuropsicológica Infantil Breve" (Solovieva \& Quintanar, 2009), which are based on the methodology of the neuropsychological school of A. R. Luria (1995a). It includes tasks that assess the functional status of the neuropsychological factors of: 1) Regulation and Control (RC); 2) Audio-verbal Retention (AVR); 3) Sequential organization (SO); 4) Visual retention (VR); 5) Tactile Kinesthetic Integration (TKI); 6) Phonematic integration (PI); 7) Analytical Spatial Perception (ASP); 8) Global spatial perception (GSP); 9) Alertness (AS).

\subsection{Procedure}

Once the study groups were formed, the school records of each of the partici- 
pants were reviewed. A one-session individual assessment was carried out within the campus of the secondary school, the average time was 60 minutes. The implementation of the instrument was carried out by neuropsychology professionals, with the informed consent of both adolescents and their respective parents, according to the ethical principles of research on human subjects of the Declaration of Helsinki (Asociación Médica Mundial, 2013).

\subsection{Qualitative Analysis}

The qualitative neuropsychological analysis was oriented to the process and to the specific quirks of the adolescents performance in each of the evaluated tasks, as well as to the error type they presented and the help provided by the examiner during the assessment (Glozman, 2002) with the purpose of identifying strengths and weaknesses in the development of neuropsychological factors (Table 1).

Table 1. "Brief Neuropsychological Assessment for Adolescents": Assessed factors, error type and type of help provided.

\begin{tabular}{|c|c|c|}
\hline $\begin{array}{l}\text { Neuropsychological } \\
\text { factor }\end{array}$ & Error type & Type of help provided \\
\hline $\begin{array}{l}\text { Regulation and } \\
\text { control }(R C)\end{array}$ & $\begin{array}{l}\text { Impulsiveness } \\
\text { No verification }\end{array}$ & $\begin{array}{l}\text { Instruction repetition } \\
\text { Outer verbal regulation }\end{array}$ \\
\hline $\begin{array}{l}\text { Audio-verbal } \\
\text { retention }(A V R)\end{array}$ & $\begin{array}{l}\text { Imprecision during evocation } \\
\text { Change in the information order } \\
\text { Diminished volume of information }\end{array}$ & $\begin{array}{c}\text { Sentence repetition/sentence } \\
\text { fragmentation } \\
\text { Phonological help } \\
\text { Semantic help }\end{array}$ \\
\hline $\begin{array}{c}\text { Sequential } \\
\text { organization }(S O)\end{array}$ & $\begin{array}{c}\text { Perseverations } \\
\text { Lack of fluency } \\
\text { Lack of automation } \\
\text { Sequence simplification } \\
\text { Micrograph/Macrograph }\end{array}$ & $\begin{array}{c}\text { Outer verbal regulation } \\
\text { Perform the sequence model }\end{array}$ \\
\hline Visual retention ( $V R)$ & $\begin{array}{c}\text { Missing elements } \\
\text { Absence of essential and differential } \\
\text { characteristics }\end{array}$ & $\begin{array}{l}\text { Verbal orientation on the } \\
\text { number of elements }\end{array}$ \\
\hline $\begin{array}{l}\text { Tactile kinesthetic } \\
\text { integration (TKI) }\end{array}$ & $\begin{array}{c}\text { Articulatory Inaccuracies } \\
\text { Incorrect recognition of objects. } \\
\text { Place and Manner articulatory substitutions }\end{array}$ & $\begin{array}{l}\text { Stimulus repetition } \\
\text { Outer verbal regulation } \\
\text { Stimulus segmentation }\end{array}$ \\
\hline $\begin{array}{c}\text { Phonematic } \\
\text { integration }(P I)\end{array}$ & $\begin{array}{l}\text { Difficulty in the differentiation of sounds, } \\
\text { syllables or words }\end{array}$ & $\begin{array}{c}\text { Repetition or segmentation of } \\
\text { the series }\end{array}$ \\
\hline $\begin{array}{l}\text { Analytical spatial } \\
\text { perception }(A S P)\end{array}$ & $\begin{array}{c}\text { Inadequate understanding of } \\
\text { logical-grammatical sentences. } \\
\text { Error in following instructions. } \\
\text { Inadequate location of elements. } \\
\text { Rotation of figures and/or their elements. }\end{array}$ & $\begin{array}{l}\text { Sentence repetition } \\
\text { Guiding questions or request } \\
\text { verification }\end{array}$ \\
\hline $\begin{array}{c}\text { Global spatial } \\
\text { perception }(G S P)\end{array}$ & $\begin{array}{l}\text { Model disintegration. } \\
\text { Inadequate proportion and metric. }\end{array}$ & $\begin{array}{l}\text { Guiding questions or request } \\
\text { verification }\end{array}$ \\
\hline Alertness $(A S)$ & $\begin{array}{l}\text { Objective loss or inconsistency } \\
\text { during the executions. } \\
\text { Need for motivation }\end{array}$ & $\begin{array}{l}\text { Instruction repetition or } \\
\text { request verification }\end{array}$ \\
\hline
\end{tabular}

Note: the type of help provided was designed in order to qualify the level of the factor's functional weakness as well as to identify false negatives. With this, the strong and weak neuropsychological nuances were highlighted with greater acuracy. Source: authors' own elaboration. 


\subsection{Statistic Analysis}

The analysis was based on the identification of the errors, on whether it is of primary or secondary origin, the severity of the error in comparison with other participating adolescents and their corresponding level of education, and on the type of help that the examiner gave to the adolescent (Glozman, 2002). Statistical analysis was carried out based on frequency analysis according to the execution type of the adolescents of the three academic grades. The value 1 was assigned for incorrect execution, even with the help of the examiner; value 2 for correct execution, with the help of the examiner; and 3 for correct execution independently. The intergroup comparative analysis between high and low performance and between school grades was performed using the SPSS program, using the Kruskal-Wallis and Mann-Whitney U tests for contrasting the groups.

\section{Results}

The results are presented following the concept of syndromic analysis, proposed by Luria. We present the results of the neuropsychological factors identified as primary (those that underlie the errors that the adolescents presented), which are "Regulation and Control" (RC) and "Spatial Analysis and Synthesis" in the modality of "Global Spatial Perception" (GSP). It is also showed the effect of the functional weakness of the primary factors in the rest of the tasks that assess "Audio-Verbal Retention" (AVR) and "Visual Retention" (VR), and "Alertness" (AS), in the intergroup comparison.

The quantitative comparisons of the results obtained between the groups with HSP and LSP, resulted in five neuropsychological factors with statistically significant differences in favor of the HSP group: RC $(p<0.001)$, GSP $(p<0.001)$, $\operatorname{AVR}(p<0.005), \operatorname{VR}(p<0.005)$ and AS $(p<0.005)$ (Figure 1$)$.

Although quantitatively significant differences were observed in these five factors between both groups, when applying the syndromic qualitative clinical analysis, only the RC and GSP factors were considered of primary origin and the other tasks of the AVR factors, VR and AS were affected secondarily. The systemic effect in the tasks of the AVR factors (repetition and evocation of sentences) was evidenced by the identified errors: volume reduction and imprecision during the evocation, and order change of the sentence components (Table 2).

As for the tasks that assess the visual retention factor (which guarantees the stability of the mnestic traces and the volume of perception in the visual modality) again, the HSP students show better results compared to those of LSP, who obtained low scores due to reduction of the volume of elements during the reproduction without model and reproduction before heterogeneous interference, in the copy of figure series (Table 3).

Another of the neuropsychological factors identified as primary was "analysis and spatial synthesis" in the GSP modality (which guarantees the perception and adequate reproduction of the general shape, of the metric aspects and the proportions of objects). The students of the HSP group managed to integrate a 


\section{Factors Comparison between High and Low Academic Performance}

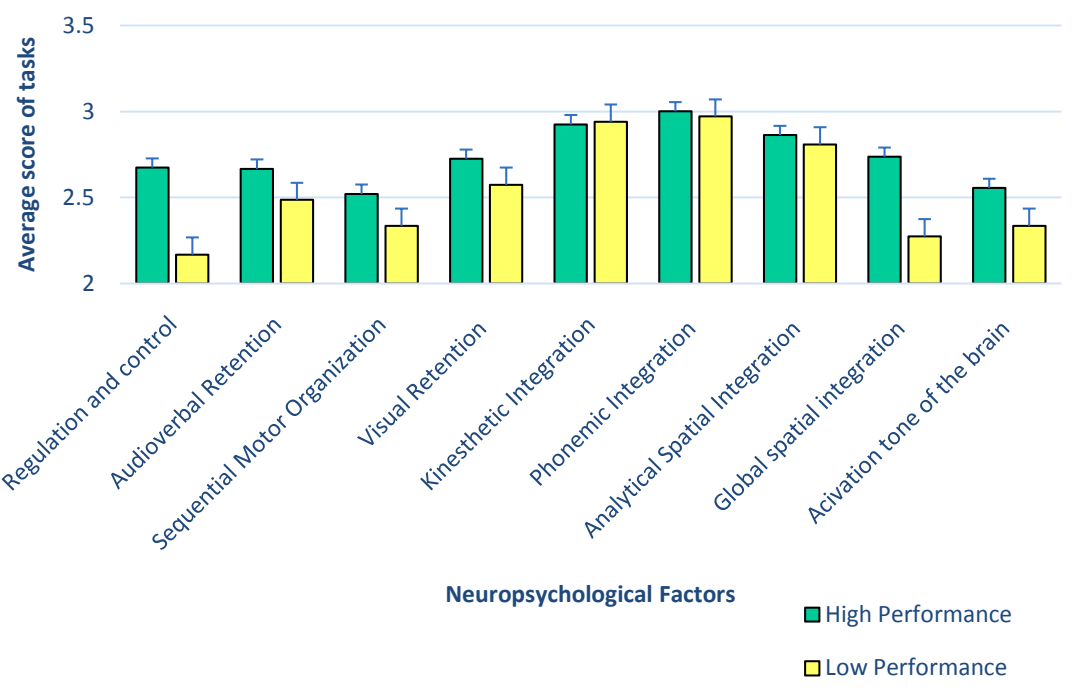

Figure 1. Comparison between obtained scores during the assessment tasks of the neuropsychological factors between high and low performance students of the three school grades. Results obtained with significant differences in favor of the HSP group: ${ }^{* *}$ significant differences, $p<0.001$; *significantdifferences, $p<0.005$. Source: authors' own elaboration.

Table 2. Performances of high and low performance students during sentence repetition task from the Instrument "Brief Neuropsychological Assessment for Adolescents".

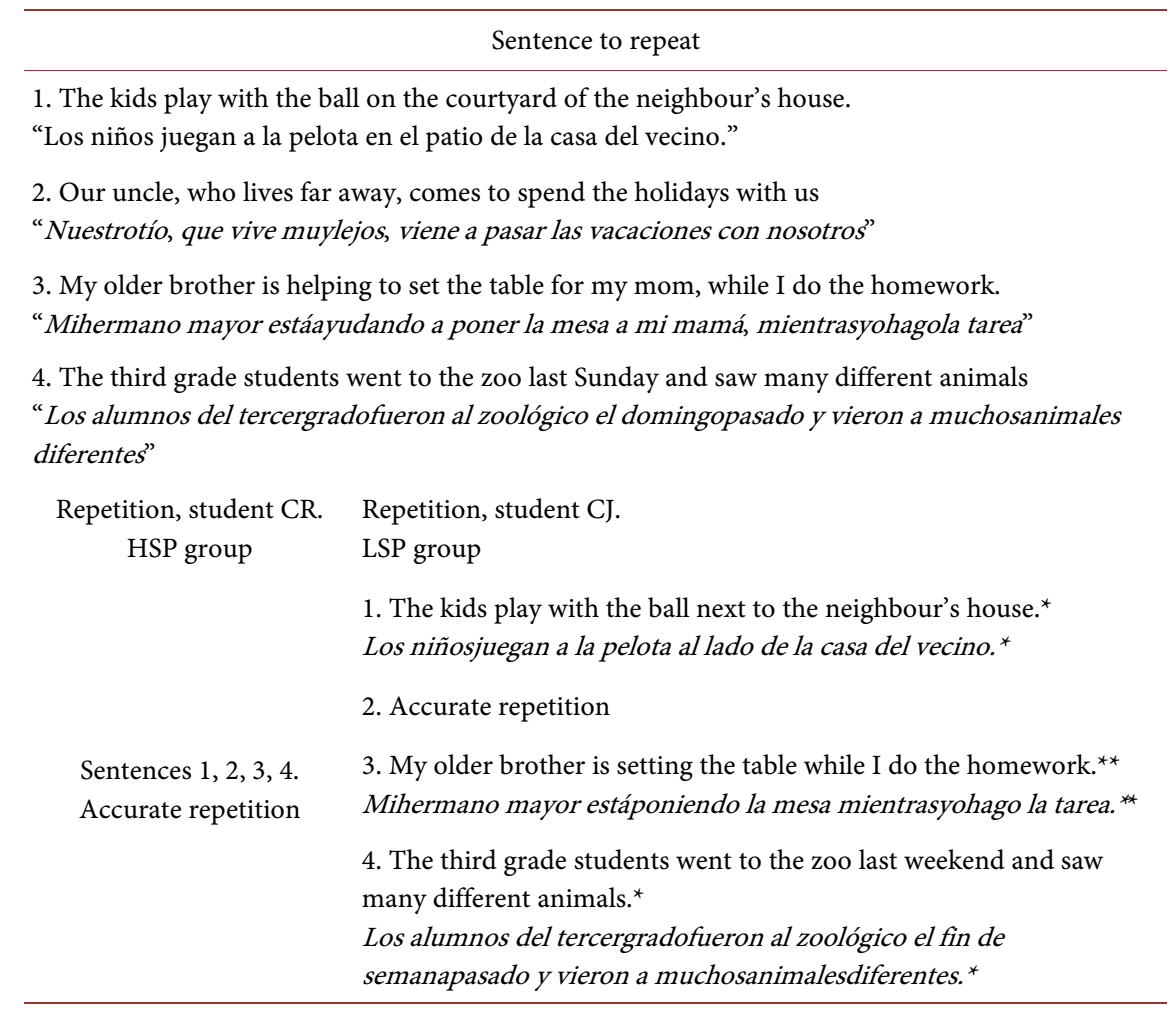

${ }^{*}$ The underlined part indicates the change of words of the adolescents, according to the sentences to be repeated. ${ }^{* *}$ Indicates sentence with word omission from the adolescent of the LSP group. Source: authors' own elaboration. 
Table 3. Performances of students with high and low school performance in the nonsense-figures repetition task.

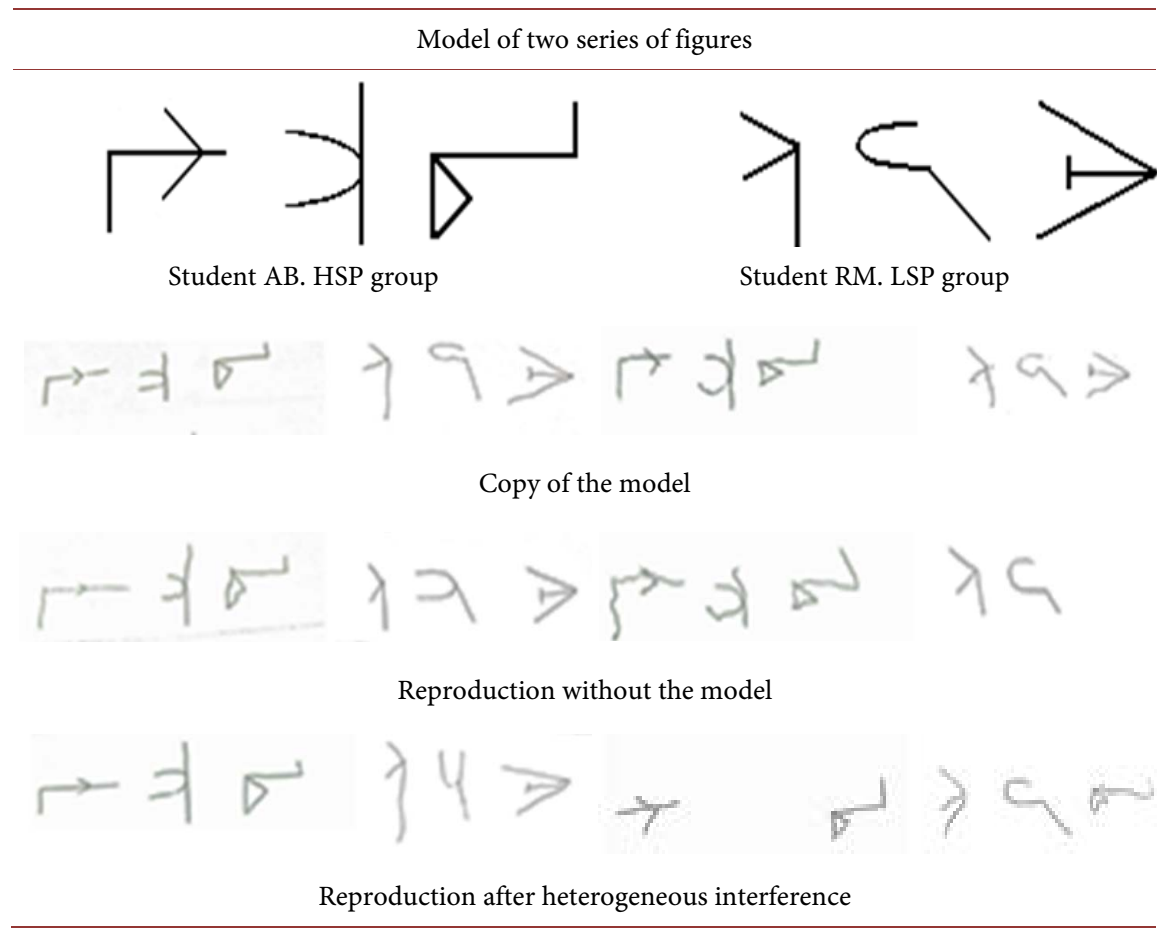

Source: authors' own elaboration.

drawing by copying, accurately, the metrics and depth. The students of LSP did not achieve this type of execution showing absence of depth (Table 4).

Finally, the tasks of the last neuropsychological factor related to the systemic effect of the primary factors of RC and GSP, were the tasks of the alertness factor, defined by Luria (Xomskaya, 2002) as the general activation background, which guarantees the stability of the execution during an action. The adolescents of the HSP group managed to set the objective of the proposed task, they stayed in the activity for the necessary time, finishing it effortlessly and without help from the examiner. While, in the LSP group, instruction repetition was needed, requiring continual motivation from the examiner to complete it, in addition to not verifying and correcting their errors on their own.

The systemic effect of the primary neuropsychological factor of RC, in the group of LSP students, was also observed during writing; spelling errors and imprecise organization of the graphic space were identified. On the other hand, errors in reading were characterized by omission of connectives or the read composition's title and by divinatory reading. These errors did not favor the comprehension of the subject read.

Regarding the comparison of student performances between the three school grades, statistically significant differences were only found for the spatial perception factor in the analytical modality (ASP) $\mathrm{U}=83.5, \mathrm{Z}=-1.691, P<0.005$; third grade students of secondary school performed adequately compared to the first and second grade, regardless of the HSP or LSP groups (Figure 2). 
Table 4. Model and copy of a house of the students of the HSP and LSP group.

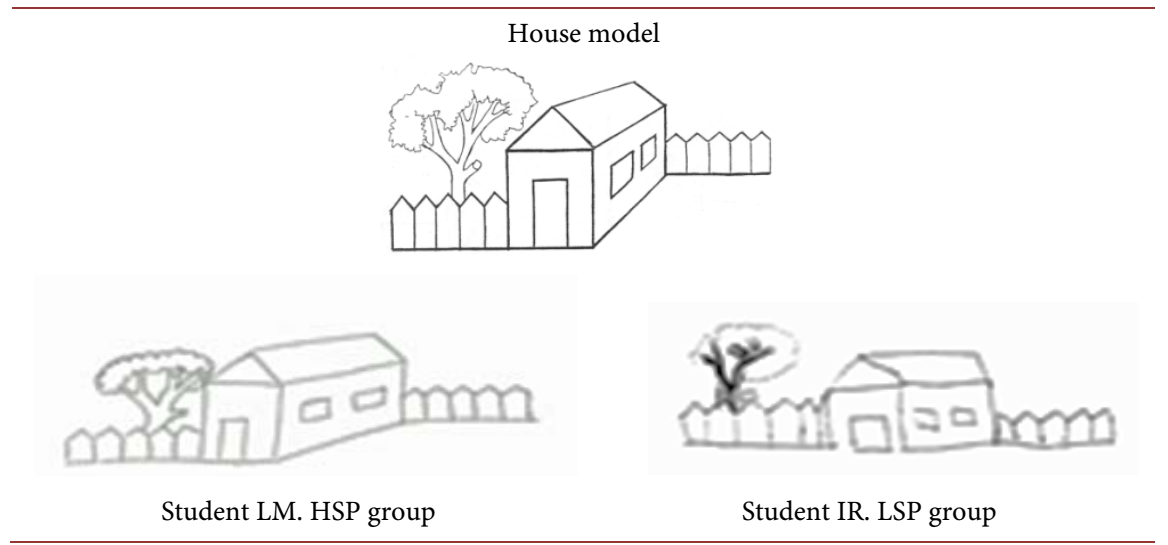

Source: authors' own elaboration.

\section{Factor Comparison between Academic Grades}
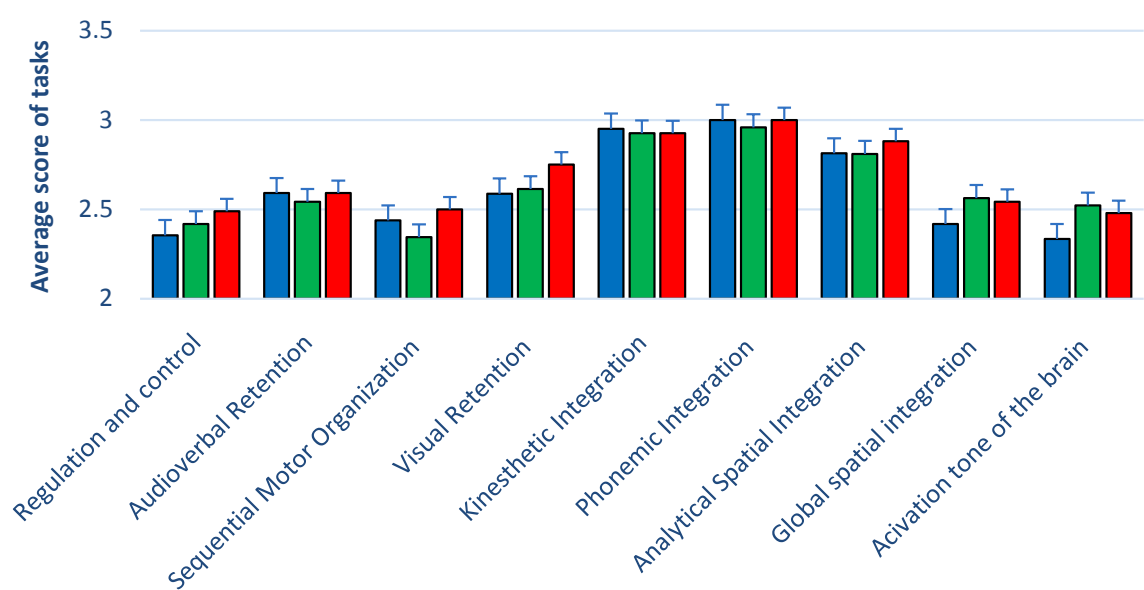

Neuropsychological Factors

$\square$ First Grade

$\square$ Second Grade

$\square$ Third Grade

Figure 2. Comparison of scores obtained in the assessment tasks of neuropsychological factors among 1st, 2 nd and 3 rd graders. ${ }^{\star}$ Significant differences, $p<0.005$; Source: authors' own elaboration.

The main errors, related to the ASP factor, (whose essential function is to guarantee the perception and adequate production of essential features and their spatial location, in addition to identifying the spatial relationships between the elements of a given situation) were found during the understanding complex logical-grammatical sentences task and follow-up instructions with quasi-spatial elements (prepositions). Other errors were inadequate location of elements in drawings and/or the elements that make them up.

\section{Discussion}

In the neuropsychological school of A. R. Luria, the location of the higher forms of mental activity is identified as complex functional systems where diverse ce- 
rebral areas that work in concert participate. This location changes during child development and in subsequent periods of learning (Luria, 1995a, 1995b). The functional changes of the different brain structures that make up the three functional blocks can help predict school success from preschool age (Blair \& Razza, 2013; Akhutina, 2002). Although complex school actions are carried out as complex functional systems, the neuropsychological factors of spatial analysis and synthesis in the modalities of global and analytical perception, and the regulation and control of activity, constitute the essential psychophysiological mechanisms for school activity in adolescence (Machinskaya, 2005). The results show that the LSP students presented errors mainly in the tasks that assess the functional level of the RC and GSP mechanisms. The functional weakness of the GSP factor negatively affects the perception and the adequate production of forms, in the conformation of letters, the general image of the word, substitution or omission of letters and difficulties in all actions that require global spatial analysis, especially in the actions in the graphic, perceptive and written language level (Akhutina, 2002; Solovieva, Lázaro, \& Quintanar, 2008).

As for the neuropsychological factor of RC, the main errors were related to the deficient execution of tasks that require maintaining an objective, which can condition difficulties during follow-up instructions, in the creation of plans, implementation of strategies of organization, verification and correction of one's own activity (Luria, 1995b; Portellano, 2018), and the effect of these difficulties could be observed in audio-verbal and visual retention tasks, where the students did not manage to maintain the volume of information and did not generate efficient memory strategies (Vygotsky, 1995a; Galperin, 2011; Bonilla, 2015; Solovieva, Bonilla-Sánchez, \& Quintanar, 2018). Neurophysiological and neurological studies indicate that the voluntary components of the cognitive activity of programming and control, selective activity and action inhibition are achieved by the maturation of the frontal-thalamic system and its links with various cortical and sub-cortical structures, around 18 years old (Machinskaya, 2005; Blakemore, Burnett, \& Dahl, 2010). However, in the adolescent population of LSP it becomes clear the need to elaborate the strategies that favor the stimulation, development and optimal maturation of the functional level of the RC mechanisms with the purpose of preventing school failure.

The school difficulties evidenced by the students of the LSP group were also related to the few interests and motivations for carrying out school activities. Talizina (2009) points out that the ways of motivation for learning can be given through two ways, one through the social sense that the student has of learning, and the other, through the same school activity that should be interesting for the student. In addition, it highlights the importance of the presence of intentions, plans, programs that are formed in the conscious life, which constitutes according to Luria (1995a) one of the main sources of cerebral activation, thus guaranteeing the energy background and the stability of the execution of actions. This could probably support the fact that LSP students also obtained statistically sig- 
nificant differences in the performance of tasks that assess the neuropsychological factor of AS compared to the HSP group, since none of the participating students had brain activation difficulties, or alertness during the activity.

When considering the results by school grade, without taking into account the low or high performance, significant differences in favor of the third-year secondary group were identified, mainly in the tasks of the ASP factor, the students achieved an adequate understanding of logical-grammatical sentences and complex quasi-spatial elements, sentences that result from complex, hierarchically constructed codes (Luria, 1995c). The understanding of this type of linguistic structures requires the maturation of the more complex left posterior zones (tertiary zones), which mature late into the adolescent age (Roselli, Ardila, Pineda, \& Lopera, 1997, Santana, 2010).

By identifying the cause of the difficulties in school activity, psychopedagogical strategies may be implemented to favor the functional level of the weak factor in the corresponding school year (Akhutina \& Pylaeva, 2012), and therefore cause a systemic effect on the various school actions, in which the weak factor participates. It is important to mention that this assessment not only provides valuable information of the children and adolescent with learning problems population (with weak functional factors) but also for the normotypical population, in order to enhance their learning. The optimal functional level of the tertiary sectors of the frontal lobes is essential for the regulation and control of the elementary motor and sensorial processes and the complex forms of perceptual, mnesic and intellectual activity, whereas the temporal-parietal-occipital sectors are important for the achievement of diverse operations, from concrete images, to logical-verbal ones (Luria, 1995a, Xomskaya, 2002). The intervention in adolescents, from this perspective, is just beginning and there is evidence of favorable results (Molina, García, Machískaya, \& Lázaro, 2013, Moreno \& Bonilla, 2013).

\section{Conclusion}

1) The findings revealed functional weakness of the neuropsychological factors of "regulation and control" and "spatial analysis and synthesis", in the global spatial perception modality, in the population with low school performance, as well as a systemic effect in tasks of visual and verbal retention and of alertness.

2) When considering the school grades, without the condition of high and low performance, significant differences were identified in favor of the third grade students on the first and second grades, in the tasks of the analytical spatial perception factor (complex language comprehension tasks).

3) The qualitative evaluation based on the syndromic analysis of the historical-cultural neuropsychology provides a useful methodology in the identification of the causes of the errors or difficulties that arise in the normotypic development conditions in adolescents.

4) According to the results shown, it is of advise to develop strategies for the 
regulation and voluntary control of various actions, as well as spatial activities of global and analytical perception in order for the students to have a better school performance.

5) The neuropsychological analysis would not only allow the creation of specific psychopedagogical strategies to overcome school difficulties, but also improve the development in optimal school-performance adolescents.

\section{Conflicts of Interest}

The authors declare no conflicts of interest regarding the publication of this paper.

\section{References}

Akhutina, T. V. (2002). Diagnosis and Correction of Writing. Spanish Journal of Neuropsychology, 4, 236-261.

Akhutina, T., \& Pylaeva, N. (2012). Overcoming Learning Disabilities. Cambridge: Cambridge University Press. https://doi.org/10.1017/CBO9781139012799

Ardila, A., \& Rosselli, M. (2007). Clinical Neuropsychology. Mexico: Modern Manual.

Asociación Médica Mundial (2013). Declaración de Helsinki de la Asociación Médica Mundial. Principios éticos para las investigaciones médicas en seres humanos. Fortaleza: 64.a Asamblea General de la AMM.

https://www.wma.net/es/policies-post/declaracion-de-helsinki-de-la-amm-principios-e ticos-para-las-investigaciones-medicas-en-seres-humanos/

Blair, C., \& Razza, R. (2013). The Importance of Behavioral Self-Regulation for School Success. In M. McClelland \& S. Tominey (Eds.), Self-Regulation and Early School Success (pp. 135-140). London: Routledge.

Blakemore, S., Burnett, S., \& Dahl, R. (2010). The Role of Puberty in the Developing Adolescent Brain. Human Brain Mapping, 31, 926-933. https://doi.org/10.1002/hbm.21052

Bodrova, E., \& Leong, D. J. (2012). Scaffolding Self-Regulated learning in Young Children: Lessons from Tools of the Mind. In R. Pianta (Ed.), Handbook of Early Childhood Education (pp. 352-369). New York: Guilford Press.

Bonilla, M. R. (2015). The Problems of Language, Attention and Memory and Their Impact in Writing. In L. Quintanar, Y. Solovieva, E. Lázaro, R. Bonilla, L. Mejía, \& J. y Eslava (Eds.), Difficulties in the Reading-Writing Process (pp. 95-125). Argentina: Witches.

Bravo, L. (2004). Perceptual Skills and Challenges in Learning to Read and Write. A Guide for the Exploration and Understanding of Specific Difficulties. News Magazine Research in Education, 4, 1-24.

Castillo-Parra, G., Gómez, E., \& Ostrosky-Solís, F. (2009). Relationship between Cognitive Functions and the Level of Academic Performance in Children. Neurology, Neuropsychiatry and Neurosciences, 9, 41-54.

Córdoba, E. M., Quijano, M. C., \& Cadavid, N. (2013). Reading Habits in Parents of Children with and without Reading Delay in the City of Cali, Colombia. CES Psychology Magazine, 6, 53-65.

Cotton, K. (2011). Neuropsychology of Adolescent Development (12 to 18 Years Old). In A. S. Davis (Ed.), Handbook of Pediatric Neuropsychology (pp. 47-58). New York: Springer Publishing Company. 
Edel, N. R. (2003). Academic Performance: Concept, Research and Development. Ibero-American Magazine on Quality, Efficiency and Change in Education, 1. https://revistas.uam.es/index.php/reice/article/view/5354

Fabes, R., Eisenberg, N., Jones, S., Smith, M., Guthrie, I., Poulin, R., Shepard, S., \& Friedman, J. (1999). Regulation, Motionality, and Preschoolers' Socially Competent Peer Interactions. Child Development, 70, 432-442.

https://www.jstor.org/stable/1132098 https://doi.org/10.1111/1467-8624.00031

Galperin, P. Ya. (2011). The Directions of the Learning Process. In L. Quintanar \& Y. y Solovieva (Eds.), Higher Psychological Functions in the Development of the Child (pp. 113-119). México: Trillas.

Glozman, J. (2002). The Quantitative Assessment of the Data of the Neuropsychological Evaluation of Luria. Spanish Journal of Neuropsychology, 4, 179-196.

Luria, A. R. (1986). The Brain in Action. Barcelona: Martínez Roca.

Luria, A. R. (1995a). The Upper Cortical Functions of Man. México: Fontamara. https://doi.org/10.1007/978-1-4684-7741-2

Luria, A. R. (1995b). Thought and Language. España: Paidós.

Luria, A. R. (1995c). Consciousness and Language. Madrid: Visor.

Machinskaya, R. (2005). Functional Maturation of the Brain and Formation of the Neurophysiological Mechanisms of Selective Voluntary Attention in Young Schoolchildren. Human Pshysiology, 32, 20-29. https://doi.org/10.1134/S0362119706010038

Machinskaya, R. I., Semenova, O. A., Absatova, K. A., \& Sugrobova, G. A. (2014). Neurophysiological Factors Associated with Cognitive Deficits in Children with ADHD Symptoms: EEG and Neuropsychological Analysis. Psychology \& Neuroscience, 7, 461-473.

https://doi.org/10.3922/j.psns.2014.4.05

Méndez, Del R. M. (2015). The Strategic Teaching of Reading Comprehension: Scientific and Educational Analysis of the Instructional Field. PhD Thesis, León: University of León.

Molina, N., García, M., Machískaya, R., \& Lázaro, E. (2013). Neuropsychological Intervention in a Teenager with Learning Problems. Case Study. Latin American Neuropsychology, 5, 37-48.

Moreno, A., \& Bonilla, M. R. (2013). Neuropsychological Intervention in Adolescents with Learning Problems. Case Analysis. Latin American Neuropsychology, 5, 47-59.

Muñoz, M. L. (1993). Comparative Study of Some Factors That Affect Academic Performance in a Population of Upper and Upper Secondary Students. PhD, México: Ibero American University.

Portellano, J. A. (2018). Neuroeducation and Executive Functions. Madrid: Omagraf.

Quintanar, L., \& Solovieva, Y. (2008). Historical-Cultural Approach: Theoretical-Methodological Foundations. In J. Eslava-Cobos, L. Mejía, L. Quintanar, \& Y. Solovieva (Eds.), Learning Disorders: Neuropsychological Perspectives (pp. 145-181). Bogotá: Cooperativa Editorial Magisterio.

Roselli, M., Ardila, A., Pineda, D., \& Lopera, F. (1997). Child Neuropsychology. Medellín: Creative Press.

Santana, R. (2010). Objectivity and Subjectivity in the Neuropsychological Assessment. Biik Projects.

Solovieva, Y., \& Quintanar, L. (2009). Brief Infant Neuropsychological Evaluation. Puebla: Autonomous University of Puebla. 
Solovieva, Y., Bonilla, R., \& Quintanar, L. (2006). Neuropsychological Analysis of Learning Problems in Adolescents. Clinical Sciences Journal, 7, 55-63.

Solovieva, Y., Bonilla-Sánchez, M. R., \& Quintanar, R. L. (2018). Neuropsychological Assessmente of Adolescents with Learning Disabilities. Journal of Education, Society and Behavioural Science, 26, 1-14. https://doi.org/10.9734/JESBS/2018/43737

Solovieva, Y., Lázaro, E., \& Quintanar, L. (2008). Historical-Cultural Approach: Evaluation of Learning Disorders. In J. Eslava-Cobos, L. Mejía, L. Quintanar, \& Y. Solovieva (Eds.), Learning Disorders Neuropsychological Perspectives (pp. 183-226). Cundinamarca: Magisterio.

Solovieva, Y., Machinskaya, R., Quintanar, L., Bonilla, R., \& Pelayo, H. (2009). Neuropsychology and Electrophysiology of ADD in the Preschool Age. Mexico: Benemérita Autonomous University of Puebla.

Solovieva, Y., Quintanar, L., \& Lázaro, E. (2006). Sociocultural Effects on Psychological and Neuropsychological Development in Preschool Children. Hispanic American Journal of Psychology, 6, 9-20.

Talizina, N. (2009). The Theory of Activity Applied to Teaching. Puebla: Benemérita Autonomous University of Puebla.

Valeri, G. (2011). Development of Executive Function. In D. Riva, Ch. Njiokiktjien, \& S. Bulgheroni (Eds.), Brain Lesion Localization and Developmental Functions (pp. 41-52). Montrouge: John Libbey Eurotext.

Venneri, A., Cornoldi, C., \& Garuti, M. (2003). Arithmetic Difficulties in Children with Visuospatial Learning Disability (VLD). Child Neuropsychology, 9, 175-183. https://doi.org/10.1076/chin.9.3.175.16454

Vygotsky, L. (1995a). Selected Works. Tome III. Madrid: Visor.

Vygotsky, L. (1995b). Thought and Language Spain: Paidós.

Xomskaya, E. (2002). The Problem of Factors in Neuropsychology. Spanish Journal of Neuropsychology, 4, 151-167. 